\title{
Isoniazid- and rifampicin-induced thrombocytopenia
}

\author{
Fatih Yakar ${ }^{1 *}$, Namşan Yildiz' ${ }^{2}$ Aysun Yakar ${ }^{3}$ and Zeki Kilıçaslan²
}

\begin{abstract}
Treatment of tuberculosis has many side effects. Thrombocytopenia is a serious side effect of such treatment and occurs mostly due to rifampicin (RIF). There are very few reported cases of thrombocytopenia due to isoniazid $(\mathrm{INH})$. An 18-year-old female patient was diagnosed with smear-positive pulmonary tuberculosis. A four-drug regimen [INH, RIF, ethambutol (EMB), and pyrazinamide (PZA)] was given. After the development of thrombocytopenia, the drug treatment was stopped, and a thrombocyte suspension was given until a normal thrombocyte count was obtained. After several start-stop trials, first INH and then RIF were identified as the possible causes of thrombocytopenia and were removed from the regimen. The patient was treated with EMB, streptomycin, PZA, and moxifloxacin with no further development of thrombocytopenia. The current case shows that antituberculosis drugs other than RIF and PZA may be responsible for the development of thrombocytopenia.
\end{abstract}

Keywords: Drug toxicity, Thrombocytopenia, Tuberculosis

\section{Background}

Tuberculosis is a chronic granulomatous infection that has caused mortality and morbidity for centuries. Treatment of this disease is problematic because of its long duration and compliance problems. One of the most important factors causing low compliance is the adverse effects of the drugs. Some of them are self-limiting, but some require treatment cessation. Common adverse effects are hepatotoxicity, hypersensitivity reactions, loss of vision, loss of hearing, flu-like syndrome, hemolytic anemia, acute renal failure, shock, neuropathy, arthralgia, and thrombocytopenia [1]. Although rare, severe thrombocytopenia may be lifethreatening. Here we describe the case of a patient affected with thrombocytopenia caused by isoniazid (INH) and rifampicin (RIF).

\section{Case presentation}

An 18-year-old female with no known disease history was admitted to another center with complaints of coughing with sputum and weight loss. Chest $\mathrm{x}$-ray and microscopic examination of the sputum enabled a diagnosis of smearpositive pulmonary tuberculosis. A four-drug regimen

\footnotetext{
* Correspondence: fyakar@yahoo.com

'Department of Pulmonary Medicine, Bezmialem Vakif University, 34093,

Fatih, Istanbul, Turkey

Full list of author information is available at the end of the article
}

(INH, $300 \mathrm{mg} /$ day; RIF, $450 \mathrm{mg} /$ day; ethambutol [EMB], $1,250 \mathrm{mg} /$ day; and pyrazinamide [PZA], $1,500 \mathrm{mg} /$ day) was started according to her weight of $50 \mathrm{~kg}$. While normal at the start of therapy $\left(300,000 / \mathrm{mm}^{3}\right)$, her thrombocyte count began to decrease during the second day of treatment $\left(18,000 / \mathrm{mm}^{3}\right)$. The therapy was stopped, and after transfusions of fresh frozen plasma and a thrombocyte suspension, her thrombocyte count became normal. Rifampicin was assumed to be the causative factor of thrombocytopenia, and therapy was restarted with INH, PZA, and EMB. However, thrombocytopenia relapsed during this regimen. The treatment was stopped and the patient was referred to our hospital.

When the patient was admitted to our hospital, her main complaint was coughing. No important previous history was present. Physical examination findings were normal with the exception of bilateral ecchymoses on her lower extremities. Chest X-ray showed a cavity with peripheral infiltration in the left upper zone. Laboratory findings revealed; sedimentation rate: $46 \mathrm{~mm} / \mathrm{hr}$, CRP: $24 \mathrm{mg} / \mathrm{lt}$, WBC: $9,910 / \mathrm{mm}^{3}$, hemoglobin: $10 \mathrm{gr} / \mathrm{dl}$, hematocrit: $31 \%$, and thrombocytes: $135,000 / \mathrm{mm}^{3}$. Other parameters were noncontributory.

Because of the recurrent thrombocytopenia, we planned to start a treatment with a single agent and add the others one by one. The treatment was initiated in our hospital with 
$\mathrm{INH}$ at $300 \mathrm{mg} /$ day, but this resulted in thrombocytopenia $\left(30,000 / \mathrm{mm}^{3}\right)$ on the third day, and the therapy was stopped. As soon as the thrombocyte count became normal, we began a three-drug regimen according to the patient's weight: PZA, $1,500 \mathrm{mg} /$ day; streptomycin (SM), $750 \mathrm{mg} /$ day; and EMB, 1,250 mg/day. Because the thrombocyte count was normal $\left(225,000 / \mathrm{mm}^{3}\right)$, INH was again added to the regimen, but on the second day of INH initiation, the thrombocyte count decreased to $10,000 / \mathrm{mm}^{3}$. The INH was stopped and the patient underwent a consultation in the Hematology Department. Then a thrombocyte suspension and methylprednisolone $(1 \mathrm{mg} / \mathrm{kg} /$ day $)$ were given. During the follow up, the thrombocyte count became normal and the methylprednisolone therapy was stopped. After re-initiation of the three-drug regimen (EMB, PZA, and SM), RIF at $450 \mathrm{mg}$ /day was added to the therapy as the fourth drug. On the third day of RIF therapy, the thrombocyte count decreased to $34,000 / \mathrm{mm}^{3}$ and RIF was ceased.

Because of thrombocytopenia caused by both INH and RIF, moxifloxacin at $400 \mathrm{mg} /$ day was added to the treatment regimen. Without INH and RIF, patient had no further thrombocytopenia development during the period of therapy. After the first month of the therapy, her sputum smear was negative. There were no clinical or laboratory abnormalities during follow up examinations. After cessation of SM in the second month, the antituberculosis treatment regimen was continued and completed with three drugs (EMB, $1250 \mathrm{mg} /$ day; PZA, $1500 \mathrm{mg} /$ day; and moxifloxacin, $400 \mathrm{mg} /$ day) without any further complications.

\section{Discussion and conclusions}

Although there are reports of thrombocytopenia during antituberculosis treatment, only few case reports of INH-induced thrombocytopenia are reported [2-5], but none where the hematologic disorder was at the same time caused by INH and RIF. Our patient had recurrent episodes of thrombocytopenia due to INH and RIF, either together or separately.

A thrombocyte count of $<150,000 / \mathrm{mm}^{3}$ is defined as thrombocytopenia. However, $2.5 \%$ of the normal population may have thrombocyte levels lower than this value [6]. The main mechanisms of thrombocytopenia are decreased production or increased destruction. Moreover, dilutional and distributional mechanisms may contribute. Before diagnosing thrombocytopenia, pseudothrombocytopenia, which may occur due to ineffective anticoagulation in blood tubes, thrombocyte clustering, or abciximab use, should be excluded [7]. In our patient, pseudothrombocytopenia was excluded with a peripheral blood smear examination.

Drug-induced thrombocytopenia is a frequent condition. George et al. collected case reports of drug-induced thrombocytopenia and defined the standard criteria with whom to explain the association between the drugs and thrombocytopenia [8]. They defined four criteria: 1) the suspected drug preceded thrombocytopenia and recovery was complete and sustained after the drug withdrawal 2) The suspected drug was the only drug used prior to the onset, or other drugs were continued or reintroduced after discontinuation of the suspected drug with a sustained normal thrombocyte count. 3) Other etiologies of thrombocytopenia were excluded. 4) Re-exposure to the suspected drug resulted in recurrent thrombocytopenia. If the suspected drug meets all criteria, then the level of evidence is definite. If it meets the first three, it is probable; if it meets only the first criterion, it is possible; and if the first criterion is not met, then it is unlikely that it is the responsible agent. According to these criteria, both INH and RIF in our patient met all of the criteria, and so the level of evidence was definite.

Clinical findings usually appear when the thrombocyte count decreases under a certain level. When thrombocytes are lower than $20,000 / \mathrm{mm}^{3}$, spontaneous bleeding and ecchymoses may appear. There were ecchymoses on both lower extremities of the present patient at admittance. RIF is the most common cause of thrombocytopenia among antituberculosis drugs. The drug binds noncovalently to membrane glycoproteins to produce compound epitopes or induce conformational changes for which antibodies are specific [8]. In addition, RIF-dependent antibodies attach to thrombocytes and cause increased destruction.

INH is a synthetic chemical and a pyridine derivative of nicotinamide. The central nervous system, liver, and hematological system are the main targets of INH toxicity. It may induce acute or chronic disturbances of the hematological system. Acutely it may cause leukocytosis, and chronically it may determine anemia (hemolytic, sideroblastic, aplastic, or megaloblastic), agranulocytosis, eosinophilia, or thrombocytopenia; disseminated intravascular coagulation and lymphadenopathy due to hypersensitivity reactions have also been reported [9]. The exact mechanism of INH-induced thrombocytopenia is not known.

Although INH-induced thrombocytopenia has been defined previously, there are only four previous cases in the literature, none of which was also RIF-induced. INHand RIF-induced thrombocytopenia in the present case was diagnosed by the occurrence of thrombocytopenia due to RIF in the treatment regimen without INH as well as thrombocytopenia due to INH in the regimen without RIF and exclusion of other potential diagnoses by a peripheral blood smear. Nevertheless, thrombocytopenia is rare but life-threatening. Early recognition and cessation of treatment may prevent mortality and morbidity.

\section{Consent}

Written informed consent was obtained from the patient for publication of this report and any accompanying images. 


\section{Competing interests}

The authors declare that they have no competing interests.

\section{Author details}

'Department of Pulmonary Medicine, Bezmialem Vakif University, 34093, Fatih, Istanbul, Turkey. ${ }^{2}$ Department of Pulmonary Medicine,

IstanbulUniversity, Istanbul Medical Faculty, Istanbul, Turkey. ${ }^{3}$ Department of Pulmonary Medicine, Malatya State Hospital, Malatya, Turkey.

Received: 30 October 2012 Accepted: 28 January 2013

Published: 13 February 2013

\section{References}

1. Blumberg HM, Burman WJ, Chaisson RE, Daley CL, Etkind SC, Friedman LN, Fujiwara P, Grzemska M, Hopewell PC, Iseman MD, Jasmer RM, Koppaka V, Menzies RI, O'Brien RJ, Reves RR, Reichman LB, Simone PM, Starke JR, Vernon AA, American Thoracic Society, Centers for Disease Control and Prevention and the Infectious Diseases Society: American thoracic society/ centers for disease control and prevention/infectious diseases society of America: treatment of tuberculosis. Am J Respir Crit Care Med 2003, 167:603-662.

2. Guy C, Broyet C, Albengres E, Berthoux F, Ollagnier M: Thrombopenia caused by isoniazid. Therapie 1993, 48(5):490-491.

3. Schlegel H, Sadoun D, Le Roux G, Guillevin L, Battesti JP: Thrombopenia induced by isoniazid. Ann Med Interne (Paris) 1991, 142(8):630.

4. Hansen JE: Hypersensitivity to isoniazid with neutropenia and thrombocytopenia. Am Rev Respir Dis 1961, 83:744-747.

5. Laub DR Jr: Isoniazid causing drug-induced thrombocytopenia. Eplasty 2011, 11:ic10,

6. Buckley MF, James JW, Brown DE, Whyte GS, Dean MG, Chesterman CN Donald JA: A novel approach to the assessment of variations in the human platelet count. Thromb Haemost 2000, 83(3):480-484.

7. Landaw SA, George JN: Approach to the adult patient with thrombocytopenia. UpToDate version 19.3. Last topic update 27 September, 2011; 2011. http://www.uptodate.com/contents/approach-to-the-adultpatient-with-thrombocytopenia.

8. George JN, Raskob GE, Shah SR, Rizvi MA, Hamilton SA, Osborne S, Vondracek T: Drug induced thrombocytopenia a systematic review of published case reports. Ann Intern Med 1998, 129:886-890.

9. Isoniazid drug information: International Programme on Chemical Safety, Poisons Information Monograph 288. http://www.inchem.org/documents/ pims/pharm/pim288.htm. Last accessed February 11, 2013.

doi:10.1186/2049-6958-8-13

Cite this article as: Yakar et al:: Isoniazid- and rifampicin-induced thrombocytopenia. Multidisciplinary Respiratory Medicine 2013 8:13.

\section{Submit your next manuscript to BioMed Central and take full advantage of:}

- Convenient online submission

- Thorough peer review

- No space constraints or color figure charges

- Immediate publication on acceptance

- Inclusion in PubMed, CAS, Scopus and Google Scholar

- Research which is freely available for redistribution

Submit your manuscript at www.biomedcentral.com/submit 